\title{
SENAM NIFAS DAN MOBILISASI DINI TERHADAP PENURUNAN FUNDUS UTERI PADA IBU POST PARTUM DI PUSKESMAS TEMINDUNG
}

\author{
Rahmawati Wahyuni ${ }^{1)}$ Nursari Abdul Syukur ${ }^{2}$ \\ ${ }^{1) 2}$ Kebidanan, Poltekkes Kemenkes Kaltim, Jl. Wolter Monginsidi No.38, Samarinda, \\ Kode Pos 75123 \\ E-mail: yunibid@gmail.com
}

\begin{abstract}
Postpartum bleeding can be caused by uterine atony, laceration, retensio placenta, utero inversion and blood clotting. In general, by puerperal gymnastics, it can accelerate the process of restoring the condition of mothers after childbirth and prevent possible complications during the time of the puerperium. The purpose of this study was to determine the effect of puerperal gymnastics on the decrease in fundal height of postpartum mothers in the Puskesmas Temindung. This research is a pre experimental research with pre test-post test control group design. The subject of the study was all post partum mothers who gave birth at the Puskesmas Temindung in August-October 2019. Samples consisted of 2 groups with 48 respondents, which were selected using the consecutive sampling technique. Analysis of independent Ttest statistics with significance level 0.05. The results showed a significant difference from the decline of TFU in the post-partum mother between the group doing puerperal gymnastics and not puerperal gymnastics in the Puskesmas Temindung proved with P-value $<0.05$. In this study show that there was an influence of puerperal gymnastics on the decrease in fundal height of postpartum mothers in the Puskesmas Temindung .
\end{abstract}

\section{Keywords:, Postpartum, puerperal gymnastics, high fundal uterine}

\begin{abstract}
Abstrak
Perdarahan post partum dapat disebabkan oleh atonia uteri, robekan jalan lahir, retensio plasenta, inversio uteri dan pembekuan darah. Pada umumnya dengan melakukan senam nifas maka dapat mempercepat proses pemulihan kondisi ibu setelah melahirkan dan mencegah komplikasi yang mungkin terjadi selama masa nifas. Penelitian ini bertujuan mengetahui pengaruh senam nifas terhadap penurunan tinggi fundus uteri pada ibu post partum di Wilayah Kerja Puskesmas TemindungSamarinda. Penelitian ini merupakan penelitian pre experimental dengan pre test-post test control group design. Subjek penelitian yang diambil adalah semua ibu post partum yang melahirkan di Wilayah Kerja Puskesmas Temindung pada bulan Agustus-Oktober 2019. Sampel sebesar 2 kelompok dengan 48 responden menggunakan teknik consecutive sampling. Analisis statistik uji t independen dengan signifikansi 0,05. Berdasarkan hasil uji statistik, terdapat perbedaan penurunan tinggi fundus uteri yang bermakna antara pre dan post pada kelompok senam nifas dan mobilisasi dini dibandingkan dengan kelompok yang tidak senam nifas dengan $p$-value $<0,05$ sehingga dapat disimpulkan terdapat pengaruh senam nifas terhadap penurunan tinggi fundus uteri pada ibu post partum di Wilayah Kerja Puskesmas Temindung.
\end{abstract}

Kata kunci:, Post partum, senam nifas, tinggi fundus uteri 


\section{PENDAHULUAN}

Angka kematian ibu (AKI) adalah salah satu indikator yang dapat menggambarkan kesejahteraan masyarakat di suatu Negara. Menurut data World Health Organization (WHO), angka kematian ibu di dunia pada tahun 2015 adalah 216 per 100.000 kelahiran hidup atau diperkirakan jumlah kematian ibu adalah 303.000 kematian dengan jumlah tertinggi berada di negara berkembang yaitu sebesar 302.000 kematian. Angka kematian ibu di Negara berkembang 20 kali lebih tinggi dibandingkan angka kematian ibu di negara maju yaitu 239 per 100.000 kelahiran hidup (WHO, 2015)

Angka Kematian Ibu di Indonesia termasuk tinggi diantara negara-negara ASEAN. Berdasarka Survei Demografi dan Kesehatan Indonesia (SDKI) tahun 2012, angka kematian ibu di Indonesia masih tinggi sebesar 359 per 100.000 kelahiran hidup. Data ini merupakan acuan untuk mencapai target AKI sesuai Sustainable Development Goals (SDG) yaitu 70 per 100.000 kelahiran hidup pada tahun 2030 (Kemenkes, 2015)

Menurut Dinas Kesehatan Kota Samarinda, angka kematian ibu (AKI). Pada tahun 2016 menunjukan angka kematian ibu yakni 40 per 100.000 kelahiran dan pada tahun 2017 terjadi peningkatan yang signifikan yakni 91 per 100.000 kelahiran.

Kematian ibu di Indonesia tahun 2013 masih didominasi oleh tiga penyebab utama kematian yaitu perdarahan sebesar 30,13\%, hipertensi dalam kehamilan sebesar $27,1 \%$, dan infeksi sebesar 7,3\%. Partus lama juga merupakan salah satu penyebab kematian ibu di Indonesia yaitu angka kejadiannya terus meningkat yaitu $1 \%$ pada tahun 2010 , dan $1,8 \%$ pada tahun 2012. (Kemenkes RI, 2016).

Perdarahan postpartum dapat disebabkan oleh atonia uteri, robekan jalan lahir, retensio plasenta, sisa plasenta, inversio uteri dan kelainan pembekuan darah. Pada saat persalinan penyebab kematian ibu adalah perdarahan yang disebabkan antara lain atonia uteri 50$60 \%$, retensio plasenta $16-17 \%$, sisa plasenta $23-24 \%$, laserasi jalan lahir 4$5 \%$, kelainan darah $0,5-0,8 \%$ (Wuryanti, 2010)

Perdarahan post partum dapat terjadi akibat kegagalan miometrium untuk berkontraksi setelah persalinan sehingga uterus dalam keadaan relaksasi penuh, kurang baik dan lembek. Salah satu cara agar kontraksi otot -otot uterus tetap baik sampai akhir nifas yaitu dengan mobilisasi dini dan gerakan sederhana 
seperti senam nifas. Karena senam nifas merupakan latihan peregangan otot-otot yang dilakukan setelah persalinan (Indriarti, 2009).

Kebanyakan ibu nifas takut untuk melakukan pergerakan, mereka khawatir gerakan yang dilakukan justru menimbulkan dampak seperti nyeri dan perdarahan. Sehingga masih banyak ibuibu nifas takut untuk bergerak dan menggunakan sebagian waktunya untuk tidur terus-menerus (Nugroho, 2014).

Ibu yang melahirkan secara normal bisa melakukan mobilisasi 6 jam atau 8 jam setelah bersalin untuk ibu yang menjalani sesar. Setelah 24 jam masa operasi sesar, dampak obat bius menghilang, ibu harus belajar menggerakkan seluruh persendian tubuh secara perlahan. Bila ibu hanya berdiam diri, pembuluh darah dan otototot tubuh, terutama di daerah kaki dan panggul akan terganggu dan berisiko memunculkan tersumbat bekuan darah (Sinsin, 2008).

Salah satu bentuk mobilisasi setelah bersalin adalah senam nifas. Senam ini bermanfaat untuk memperbaiki sirkulasi darah, memperbaiki sikap tubuh, memperbaiki kekuatan otot panggul, otot perut, dan otot tungkai bawah. Tentu saja, senam nifas ini harus dilakukan secara bertahap (Sinsin, 2008).
Senam nifas ini dapat dilakukan pada semua ibu nifas bahkan pada ibu yang tidak terbiasa berolahraga karena gerakannya cukup sederhana tapi terbukti mampu memulihkan segera kondisi ibu setelah bersalin dan menjaga stamina ibu (Suherni dkk, 2010).

Berdasarkan uraian tersebut dan banyak kasus ibu nifas yang mengalami permasalahan, oleh sebab itu penulis tertarik untuk studi eksperimen dengan melakukan penelitian yang bertujuan untuk menganalisis mengenai pengaruh senam nifas terhadap penurunan tinggi fundus uteri pada ibu post partum.

\section{METODE PENELITIAN}

Jenis penelitian yang digunakan dalam penelitian ini adalah quasi experimental dengan desain pre-test post-test control group, untuk menganalisis pengaruh dan perbedaan penurunan tinggi fundus antara kelompok intervensi dan kelompok kontrol.

Waktu penelitian ini dilaksanakan pada tanggal 20 Agustus 2019 yang berlokasi di Wilayah Kerja Puskesmas Temindung Samarinda. Populasi dalam penelitian ini adalah seluruh ibu post partum yang melahirkan di Wilayah Kerja Puskesmas Temindung Samarinda. Sampel yang akan diambil dari penelitian ini adalah 
ibu post partum yang memenuhi kriteria inklusi. Variabel bebas pada penelitian ini adalah senam nifas dan variable terikat yaitu penurunan tinggi fundus uteri pada post partum di Wilayah Kerja Puskesmas Temindung Samarinda.

Adapun kriteria inklusi dalam penelitian ini adalah :

1) Ibu yang bersalin di Klinik bersalin Wilayah Kerja Puskesmas Temindung

2) Persalinan pervaginam

3) Ibu post partum hari pertama

4) Ibu post partum yang mempunyai rentang tekanan darah sistolik 110$139 \mathrm{mmHg}$ dan diastolik 70-89 $\mathrm{mmHg}$

5) Ibu post partum yang bersedia menjadi responden

Teknik pengambilan sampel adalah yaitu Consecutive sampling adalah cara pengambilan sampel yang dilakukan dengan cara memilih sampel yang

\section{HASIL DAN PEMBAHASAN}

1. AnalisisUnivariat

Analisa Univariat yang menjadi subyek atau partisipan dalam skripsi ini adalah ibu post partum di Wilayah Kerja memenuhi kriteria penelitian sampai kurun waktu tertentu sehingga jumah sampel terpenuhi (Hidayat, 2009).

Pengumpulan data yaitu data primer dan data sekunder, data primer adalah penurunan tinggi fundus uteri pada hari pertama (pre test) dan hari ke-6 (post test), sedangkan data sekunder adalah karakteristik responden meliputi usia, suku, pendidikan, dan pekerjaan yang didapatkan dari status pasien. Setelah sampel terpenuhi peneliti membagi menjadi dua kelompok yaitu kelompok intervensi dan kontrol.

Analisis bivariat dilakukan terhadap dua variabel yang diduga berhubungan atau berkorelasi. Analisis bivariat dalam penelitian ini bertujuan untuk menguji perbedaan penurunan tinggi fundus uteri pada ibu post partum yang melakukan senam nifas dan tidak senam nifas.

Puskesmas TemindungSamarinda, yang terdiri dari umur, suku, pendidikan, dan pekerjaan dalam bentuk tabel frekuensi dan presentase. Hal ini dapat dilihat pada tabel-tabel dibawah ini :

Tabel 1. Distribusi Karakteristik Usia Responden Kelompok Intervensi dan Kontrol

\begin{tabular}{lcccc}
\hline Karakteristik & \multicolumn{2}{c}{ Senam Nifas } & \multicolumn{2}{c}{ Tidak Senam Nifas } \\
\hline Usia (Tahun) & (n) & \% & (n) & \% \\
20-25 tahun & 10 & $42 \%$ & 10 & $42 \%$ \\
$\mathbf{2 6 - 3 0}$ tahun & 10 & $42 \%$ & 8 & $34 \%$ \\
31-35 tahun & 4 & $16 \%$ & 4 & $16 \%$ \\
\hline
\end{tabular}




\begin{tabular}{ccccc}
\hline 36-40 tahun & - & - & 2 & $8 \%$ \\
Total & 24 & 100 & 24 & 100 \\
\hline
\end{tabular}

Sumber: Data Primer, 201

Tabel 2. Uji Normalitas Penurunan TFU pada Responden yang Senam Nifas dan Tidak Senam Nifas

\begin{tabular}{ccc}
\hline \multirow{2}{*}{ Penururan TFU } & \multicolumn{2}{c}{ Saphiro Wilk Test } \\
\cline { 2 - 3 } & Senam Nifas & Tidak Senam Nifas \\
\hline Pre Test + Post test & 0,001 & 0,005 \\
\hline
\end{tabular}

Sumber: Data Primer,2019

Tabel 1 menunjukkan karakteristik tidak senam nifas yaitu $<0,05$ dengan uji responden berdasarkan usia dari normalitas menggunakan Saphiro Wilk kelompok intervensi dan kelompok Test sehingga dapat disimpulkan bahwa control. Tabel 2 menunjukkan bahwa semua data tidak berdistribusi normal. nilai signifikasi penurunan TFU pre dan Karena data tidak berdistribusi normal post pada kelompok senam nifas dan maka dilanjutkan dengan Uji Wilcoxon.

Tabel 3 Uji Wilcoxon Penurunan TFU pada Responden yang Melakukan Senam Nifas

\begin{tabular}{llccc}
\hline \multirow{2}{*}{ Penururan TFU } & Mean Skor & \multicolumn{2}{c}{ Uji Wilcoxon } & Perbedaan \\
& Mean Skor & P-value & Keterangan \\
\hline Pre Test & 12,80 & 6,10 & 0,005 & Ada Beda \\
Post test & 6,70 & & & \\
\hline
\end{tabular}

Sumber: Data Primer, 2019

Berdasarkan tabel 3 dapat diketahui dengan Uji Wilcoxon menghasilkan $p$ bahwa nilai mean pre-test dan post-test value $0,005 \quad(<0,005)$, hal ini berarti variabel penurunan tinggi fundus uteri bahwa ada perbedaan yang signifikan masing-masing adalah 12,90 dan 5,20 terhadap penurunan tinggi fundus uteri dengan penurunan nilai mean sebesar pre-test dan post-test setelah diberikan 7,70. Sementara itu, hasil uji statistic perlakuan senam nifas.

Tabel 4 Uji Wilcoxon Penurunan TFU pada Kelompok Tidak Senam Nifas

\begin{tabular}{ccccc}
\hline $\begin{array}{c}\text { Penurura } \\
\text { n TFU }\end{array}$ & Mean Skor & Perbedaan Mean Skor & $\begin{array}{c}\text { P- } \\
\text { value }\end{array}$ & Keterangan \\
\hline Pre Test & 12,90 & & & Ada Beda \\
\hline
\end{tabular}




\section{Post test $\quad 5,20$}

$7,70 \quad 0,005$

Sumber: Data Primer,2019

Berdasarkan tabel 4, dapat diketahui bahwa nilai mean pre-test dan post-test variabel penurunan tinggi fundus uteri masing-masing adalah 12,80 dan 6,70 dengan penurunan nilai mean sebesar 6,10. Sementara itu, hasil uji statistic dengan Uji Wilcoxon menghasilkan $p$ value $0,005 \quad(<0,005)$, hal ini berarti bahwa ada perbedaan yang signifikan terhadap penurunan tinggi fundus uteri pre-test dan post-test pada kelompok tidak senam nifas.
Dengan demikian berdasarkan uji Wilcoxon, dapat disimpulkan bahwa ada pengaruh senam nifas terhadap tinggi fundus uteri dari hari pertama sampai dengan hari ke-6 post partum. Hal ini sesuai dengan penelitian yang dilakukan Fadlina pada tahun 2015 tentang pengaruh senam nifas terhadap penurunan tinggi fundus uteri, didapatkan hasil bahwa senam nifas terbukti memberikan pengaruh terhadap penurunan tinggi fundus uteri pada ibu post partum.

Tabel 5 Uji Normalitas Penurunan TFU pada Responden yang Senam Nifas dan Tidak Senam Nifas

\begin{tabular}{lcc}
\hline Penururan Tinggi Fundus Uteri & \multicolumn{2}{c}{ Saphiro Wilk Test } \\
\cline { 2 - 3 } (TFU) & Senam Nifas & Tidak Senam Nifas \\
\hline Pre Test & 0,152 & 0,149 \\
\hline Post Test & 0,149 & 0,172 \\
\hline Sumber: Data Primer,2019 & &
\end{tabular}

Tabel 5 menunjukkan bahwa nilai signifikasi penurunan TFU pre dan post pada kelompok senam nifas dan tidak senam nifas yaitu >0,05 dengan uji normalitas menggunakan Saphiro Wilk Test sehingga dapat disimpulkan bahwa semua data berdistribusi normal.

Menganalisis perbedaan penurunan TFU pre-test pada kelompok senam nifas dan kelompok tidak senam nifas, secara ringkas dapat dilihat pada Tabel 6 dibawah ini :

Tabel 6 Uji Beda Rerata Selisih Penurunan TFU Pre-Test pada Kelompok Senam Nifas dan Tidak Senam Nifas

Penurunan TFU Mean Skor P-Value $\quad$ Keterangan


Kelompok Senam Nifas

Pre-Test

Kelompok Tidak Senam Nifas

Pre-Test

Sumber: Data Primer,2019

Dari Tabel 6 karena P-value kelompok senam nifas dan kelompok 0,818<0,05 maka dapat diketahui bahwa tidak ada perbedaan Pre-test pada tidak senam nifas, secara ringkas dapat kelompok senam nifas dan kelompok

tidak senam nifas. Menganalisis

perbedaan penurunan TFU post-test pada

Tabel 7 Uji Beda Rerata Selisih Penurunan TFU Post-Test pada Kelompok Senam Nifas dan Tidak Senam Nifas

\begin{tabular}{cccc}
\hline Penurunan TFU & Mean Skor & P & Keterangan \\
\hline $\begin{array}{c}\text { Kelompok Senam Nifas } \\
\text { Post-Test }\end{array}$ & 5,20 & & \\
$\begin{array}{c}\text { Kelompok Tidak Senam Nifas } \\
\text { Post-Test }\end{array}$ & 6,70 & 0,002 & Ada Perbedaan \\
\hline
\end{tabular}

Sumber: Data Primer,2019

Pada uji Independent T-test tabel 7 nilai post test penurunan tinggi fundus uteri didapatkan nilai mean pada Kelompok senam nifasadalah 5,20 dan pada kelompok tidak senam nifas adalah 6,60 sedangkan nilai p 0,002<0,05 yang artinya Ho ditolak dan $\mathrm{Ha}$ diterima dengan demikian terdapat perbedaan yang cukup bermakna pada post test Kelompok senam nifas dan Kelompok tidak senam nifas. Jika dilihat dari ratarata penurunan tinggi fundus uteri pada kedua kelompok dapat disimpulkan bahwa terdapat perbedaan yang bermakna antara Kelompok senam nifas dan Kelompok tidak senam nifas.

\section{PEMBAHASAN}

Rata-rata tinggi fundus uteri pre test pada kelompok intervensi 12,90 cm dan rata-rata penurunan tinggi fundus uteri post test hari ke-8 adalah $5,20 \mathrm{~cm}$. Sedangkan rata-rata tinggi fundus uteri pre test pada kelompok kontrol adalah $12,80 \mathrm{~cm}$ dan rata-rata penurunan tinggi 
fundus uteri post test hari ke-6 adalah 6,7 cm. Dari pernyataan diatas dapat dilihat bahwa kedua kelompok sama-sama terjadi penurunan tinggi fundus uteri, hal ini sesuai dengan teori yaitu adanya perubahan retrogresif pada uterus yang menyebabkan berkurangnya ukuran uterus, involusi puerperium dibatasi pada uterus dan apa yang terjadi pada organ dan struktur lain hanya dianggap sebagai perubahan puerperium (Varney, 2004)

Hal ini sejalan dengan penelitian yang dilakukan oleh Maruroh (2012) pada 25 orang responden ibu post partum spontan dan didapatkan hasil bahwa ada pengaruh antara senam nifas dengan penurunan tinggi fundus uteri pada ibu post partum.

Penelitian ini juga sejalan dengan penelitian sebelumnya yaitu, Hammer (2000) menyatakan bahwa dengan adanya program latihan selama post partum dapat memperkuat pemulihan otot yang terbebani selama hamil dan persalinan, serta meningkatkan kesehatan dan kebugaran ibu post partum. Kesimpulan dari analisis ini menggambarkan bahwa program latihan yang dilaksanakan masa nifas akan memulihkan hampir seluruh organ tubuh dan proses involusi ini sangat jelas terlihat pada alat-alat kandungan.

Penelitian Surtiati dan Nawati
(2010); menyebutkan senam nifas yang dilakukan pada ibu post partum berpengaruh terhadap pemulihan fisik sembilan kali lebih baik pada ibu yang diberi intervensi senam nifas dibandingkan dengan ibu yang tidak diberikan intervensi senam nifas. Latihan fisik berupa senam nifas pada masa post partum berpengaruh terhadap pemulihan fisik ibu post partum lebih cepat. Keterangan ini menandakan bahwa pemulihan fisik termasuk involusi uterus yang dilihat dari penurunan tinggi fundus uteri.

Penelitian ini sesuai dengan yang diungkapkan oleh Maryunani dan Sukaryati (2011) bahwa dengan melakukan senam nifas dapat memulihkan kembali elastisitas dan kekakuan rahim. Hasil penelitian ini sejalan dengan penelitian yang dilakukan oleh Yuniasih (2006), mengenai pengaruh senam nifas terhadap kecepatan penurunan tinggi fundus uteri pada ibu post partum primipara hari pertama sampai hari kelima. Dengan mengikuti senam nifas, gerakan-gerakan yang ada dapat melatih dan mengencangkan otototot perut sehingga secara tidak langsung dapat merangsang otot-otot rahim agar berfungsi secara optimal dan tidak terjadi perdarahan post partum. Dengan 
demikian tujuan dilakukannya senam nifas bagi ibu hamil yaitu memperbaiki elastisitas otot-otot yang telah mengalami peregangan, meningkatkan ketenangan dan memperlancarkan sirkulasi darah, dan mengembalikan rahim pada posisi semula (involusi).Dengan melakukan senam nifas dan mobilisasi dini akan merangsang kontraksi uterus sehingga mempercepat penurunan tinggi fundus uteri.

Pada penelitian ini terdapat banyak keterbatasan peneliti, karena secara teori penurunan tinggi fundus uteri tidak hanya dipengaruhi oleh senam nifas dan mobilisasi dini saja akan tetapi terdapat faktor-faktor lain yang juga mempengaruhi penurunan tinggi fundus uteri seperti paritas, gizi/nutrisi dan proses laktasi, usia.

\section{KESIMPULAN DAN SARAN}

Berdasarkan hasil uji beda rerata, terdapat perbedaan penurunan tinggi fundus uteri yang bermakna antara pre dan post pada kelompok senam nifas dan tidak senam nifas dengan $p$-value $<0,05$ sehingga dapat disimpulkan terdapat pengaruh senam nifas terhadap penurunan tinggi fundus uteri pada ibu post partum di wilayah kerja puskesmas temindung .

Diharapkan untuk Wilayah Kerja Puskesmas Temindung Samarinda dapat menerapkan dan mengajarkan pada ibu postpartum yang akan pulang serta memberikan motivasi kepada ibu post partum untuk melakukan latihan senam nifas sehingga membantu proses pemulihan kondisi ibu pasca partus.

\section{DAFTAR PUSTAKA}

Ambarwati Retna, E, Wulandari. D.( 2008). Asuhan Kebidanan Nifas. Yogyakarta: Mitra Cendikia.

Ambarwati, E, \& Wulandari, D. (2008). Asuhan Kebidanan Nifas. Yogyakarta. Cendekia Press

Ambarwati, E,R,Diah, W. 2010. Asuhan Kebidanan Nifas. Yogyakarta: Nuha Medika.

Ambarwati. 2010. Asuhan Kebidanan Nifas. Yogyakarta : Nusa Medika Andriyani (2013). Pengaruh Senam Nifas Terhadap Penurunan Tinggi Fundus Uteri Pada Ibu Post Partum', IX. Available at: https://ejurnal.poltekkes-

tjk.ac.id/index.php/JKEP/article/vi ew/349.

Anggraini, Yetti. 2010. Asuhan kebidanan Masa Nifas. Yogyakarta : Pustaka Rihama.

Dhrma (2011) Metodologi Penelitian keperawatan. Jakarta :CV. Trans Info Media 
Fitriahadi, E. (2019) 'Pengaruh Penguatan Otot Rectus Abdominis Terhadap Penurunan Tfu Pada Ibu Postpartum Pervaginam Di Pmb Kabupaten Sleman', 8. Available At:

Https://Www.Researchgate.Net/P ublication/331072837_Pengaruh_

Penguatan_Otot_Rectus_Abdomin

is_Terhadap_Penurunan_Tfu_Pad

a_Ibu_Postpartum_Pervaginam_D

i_Bpm_Kabupaten_Sleman.

Gunawan, I. (2015) 'Tinggi Fundus Uteri Pada Ibu Post Partum Yang Melaksanakan Senam Nifas', XI. Available at:

https://ejurnal.poltekkestjk.ac.id/index.php/JKEP/article/vi ew/569.

Ineke (2016) 'Pengaruh Senam Nifas Terhadap Tinggi Fundus Uteri Dan JenisLochea Pada Primipara', Pengaruh Senam Nifas Terhadap Tinggi Fundus Uteri, 1. Available at: file:///C:/Users/CNT1102/Downloads/17-Article Text53-1-10-20180306 (4).pdf.

Kementerian Kesehatan RI (2015) Pusat

Data dan Informasi Kementerian

Kesehatan RI Jakarta : Infodatin. Marmi. 2012. Asuhan Kebidanan Pada Masa Nifas "Peurperium Care”.
Yogyakarta: pustaka pelajar.

Maryunani, A dan Sukaryati, Y. 2011. Senam Hamil, Senam Nifas, dan Terapi Musik. Jakarta: Trans Info Media

Masrikhah. (2009). Komplikasi Masa Nifas. USU, 8-39.

Notoatmodjo,S. 2012. Metodologi Penelitian Kesehatan. Jakarta: Rineka Cipta.

Profile Kesehatan Kota Samarinda Tahun 2016 dan 2017.

Purwoastuti dan Walyani. (2015). Asuhan kebidanan masa nifas dan menyusui Yogyakarta : Pustaka Baru Pres

Rullynil, N. T. (2014) 'Pengaruh Senam Nifas terhadap Penurunan Tinggi Fundus Uteri pada Ibu Post Partum di RSUP DR. M. Djamil Padang'. Available at: http://jurnal.fk.unand.ac.id/index.p hp/jka/article/view/111.

Saifuddin B, Rachimhadhi T, Winkjosastro HG. 2013. Buku Panduan Praktis Pelayanan Kesehatan Maternal dan Neonatal. Jakarta: PT Bina Putaka Sarwono Prawirohardjo

Saleha, Siti. (2009). Asuhan Kebidanan pada Masa Nifas. Jakarta: Salemba Medika. 
Sari, E. (2015). Hubungan Pengetahuan Dengan Sikap Ibu Hamil Terhadap Senam Hamil Di Rumah Sakit Elisabet Medan Tahun 2014. Jurnal Ilmiah Kebidanan

Saryono. (2008). Metodologi Penelitian Kesehatan, Penuntun Praktis bagi Pemula. Yogyakarta : Mitia Medika. Sastroasmoro,

Sinsin, I., 2008. Seri Kesehatan Ibu \& Anak. Masa Kehamilan dan Persalinan.

Sudigdo (2014). Dasar-Dasar Metodologi Penelitian Klinis. Jakarta: Sagung Seto.

Suherni, S. dkk. (2008). Perawatan Masa Nifas. Yogyakarta: Fitramaya.

Suherni, dkk, (2009). Perawatan masa nifas, cetakan ketiga. Yogyakarta: Fitramaya.

Suherni. 2008. Perawatan Masa Nifas. Yogyakarta: Fitramaya.

Sulistyawati, Ari. 2009. Buku Ajar Asuhan Kebidanan pada Ibu Nifas: Yogyakarta: C. V Andi Offset.

Sulistyawati. A. 2009. Asuhan Kebidanan Pada Masa Kehamilan. Jakarta:Salemba Medika.

Varney, Helen. 2008. Buku Ajar Asuhan Kebidanan. Volume 2. Jakarta: EGC
WHO (2015) Pusat Data dan Informasi Kementerian Kesehatan RI. Jakarta Selatan: Infodatin.

Widianti, Anggriyana Tri dan Atikah Proverawati. 2010. Senam Kesehatan, Yogyakarta: Nuha Medika.

Wiknjosastro H. ( 2009) Ilmu Kebidanan. Edisi ke-4 Cetakan ke-2. Jakarta: Yayaan Bina Pustaka Sarwono Prawirohardjo;

Yanti, RD dan Ayu, N. (2016). Hubungan Antara Pengetahuan Ibu Hamil Tentang Tanda Bahaya Dan Komplikasi Kehamilan Dengan Kepatuhan Kunjungan Antenatal Dan Pemilihan Tempat Bersalin Di Wilayah Tanah Sareal Bogor. Jurnal Ilmiah Kesehatan Diagnosis.

Yuliawati, Y., \& Anggraini, Y. (2016). Hubungan Riwayat Pre Eklamsia, Retensio Plasenta, Atonia Uteri Dan Laserasi Jalan Lahir Dengan Kejadian Perdarahan Post Partum Pada Ibu Nifas

Hasrani. (2015). Pengaruh Senam Nifas Modifikasi Terhadap ASI dan Pengeluaran Lokia Ibu Nifas di Puskesmas Mar'rang Kabupaten Pangkep. Tessis. Makassar. Program Pasca Sarjana 
Mahakam Midwifery Journal, Vol 5, No. 1, Mei 2020 : 27-37

Universitas Hasanuddin Makassar. 